\title{
Orientações para uma descolonização do conhecimento: um diálogo entre Darcy Ribeiro enrique Dussel
}

\section{Adelia Miglievich-Ribeiro* Edison Romera*}

\section{Resumo}

Esta comunicação apresenta orientações epistêmicas do antropólogo brasileiro Darcy Ribeiro (1922-1997) e, também, do filósofo argentino Enrique Dussel (1934-) - cada um deles como uma voz de grande significado para um projeto viável de descolonização do conhecimento científico e filosófico 'em' e ‘a partir da' América Latina. Tais estudiosos são aqui lembrados em algumas de suas teses e quadro analíticos originais, na interlocução com suas fontes, a fim de que se pudesse propor o pensamento de ambos, em provável diálogo, tanto no que diz respeito ao nível teórico quanto ao utópico relacionado a um projeto emancipador e autônomo latino-americano. Dessa forma, intenta-se demonstrar a complementaridade tanto quanto as intenções quanto aos problemas epistêmicos entre as perspectivas darcyniana e dusseliana, superando o modelo eurocentrado, por uma abordagem pluriversal na produção do conhecimento, defendida como necessária no debate teórico contemporâneo.

Palavras-chave: Descolonização do conhecimento. Darcy Ribeiro. Enrique Dussel. América Latina.

Universidade Federal do Espírito Santo, Brasil. 


\section{Guidelines for a decolonization of knowledge: a dialogue between Darcy Ribeiro and Enrique Dussel}

\section{Abstract}

This communication provides epistemic guidance from the works of Brazilian anthropologist Darcy Ribeiro (1922-1997) and Argentinian philosopher Enrique Dussel (1934-) - each of them an authoritative voice for a viable project of decolonization of scientific and philosophical knowledge, 'within' and 'from' Latin America. We draw on some of these scholar's original theses and analytical frameworks, as well as on their dialogue with their respective sources, in order to propose a discussion between their thoughts, at both a theoretical and a utopian level, regarding an emancipatory and autonomous Latin American project. Thus, we try to demonstrate the complementarity as to the intentions as well as to the epistemic problems, between the Darcyan and Dusselian perspectives, going beyond the Eurocentric model, through a pluriversal approach in the production of the knowledge, that is advocated as necessary also in the contemporary theoretical debate.

Keywords: Decolonization of knowledge. Darcy Ribeiro. Enrique Dussel. Latin America.

\section{Introdução}

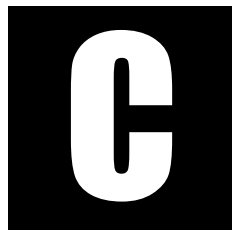

ogitar sobre a plausibilidade na elaboração de uma epistemologia para além de determinados centros hierárquicos/hegemônicos de conhecimento é tarefa, para muitos, inglória. No máximo, fruto de ressentimentos ou ainda expressão de uma ambição narcisista. Estranho mundo onde os resistentes e não os "donos do poder" recebem a pecha acusatória de trabalhar contra a ciência, sobretudo, se a entendemos como um discurso válido acerca de quem somos e como vivemos. Está bem documentado, contudo, que nossos conhecimentos são, sempre, situados (Grosfoguel, 2010, p. 459. Cf. tb.: Haraway, 1995; Lander, 
2005). Com a ciência moderna não seria diferente, nem se poderia mais ousar pensá-la dissociada do pacto colonial que fundou impérios, classificou pessoas em "humanos" e "não humanos", definiu a divisão internacional do trabalho, autorizou vozes e silenciou outras.

Um movimento contemporâneo de raízes andinas nasce em fins do século XX e reúne alguns investigadores preocupados com os efeitos nocivos da persistente divisão internacional do trabalho intelectual. Não se trata apenas disso. Em verdade, os respectivos estudiosos comungam da percepção de que o fim do colonialismo na América Latina, como relação econômica e política de dominação desde o século XIX, não implicou o fim da "colonialidade", ainda presente nas subjetividades, interações, memória, linguagem, imaginário e instituições daqueles que herdam o pesado estigma da subalternidade. Chamou-se tal movimento de modernidade-colonialidade, em sua pretensão de desvelar a face oculta da modernização, a saber, a violência da conquista e da colonização bem como seus traços de permanência no tempo e no espaço (Quijano, 2005; Castro-Gómez, 2005). Soma-se a isto, mais recentemente, a inclusão de uma terceira ponta a conformar, agora, uma tríade: a decolonialidade ou descolonialidade, isto é, a atenção às inúmeras resistências e subversões que se dão a partir das fissuras no projeto moderno, explicitando sua impossibilidade de explicar e, muito menos, de normatizar o mundo (Mignolo, 2004).

O clamor do que passou a ser, também, conhecido como "giro decolonial" ou "giro descolonial", inflexão epistêmica, ética e política nas ciências sociais latino-americanas que - chave interpretativa das questões hoje postas para o subcontinente - se tornou o desenvolvimento da competência crítica do "colonizado" para julgar o universo cognitivo do colonizador, na contramão do que se deu por séculos e ainda ocorre, a saber, a introjeção acrítica da cosmovisão alheia em sua própria psiquê que não lhe permite o pensamento autônomo. 
Expressivos representantes da perspectiva da modernidadecolonialidade-descolonialidade na América Latina, a exemplo de Enrique Dussel (Argentina/México), Aníbal Quijano (Peru), Santiago Castro-Gómez (Colômbia), Walter Mignolo (Argentina / EUA) mantêm o diálogo com as formulações da crítica pós-colonial, nascida a partir da segunda metade do século XX, no processo de libertação das colônias em África e em Ásia e com a diáspora negra, dentre outros, a produzir os chamados Estudos Culturais ${ }^{1}$. Ainda, o sociólogo português Boaventura de Sousa Santos (2002) é chamado a somar no debate a fim de matizar, do lado do "colonizador", as hierarquias que elegeram uma Europa (a anglo-saxã e germânica) superior a todas as demais, até os dias de hoje, de modo a silenciar, até mesmo, a participação dos povos ibéricos e miscigenados na criação da modernidade.

Os intelectuais descoloniais sabem que o horizonte pedagógico estabelecido pela hierarquia epistêmica colonial na modernidade é caracterizado, entre outros, pela língua nacional e pelo lugar hierárquico que ocupam essas linguagens na estrutura epistêmica de poder. A ampliação dessas formas de conhecimento, a partir do século XIX, e a própria organização das ciências sociais resultaram na desconcertante e radical hipótese de que, las lenguas adecuadas para las ciencias sociales fueron, principalmente, el francés, el inglés y el alemán (Mignolo, 2001, p. 176). Catherine Walsh (2008) caracteriza esta formação e articulação epistemológicas como uma das faces mais evidentes da "colonialidade do saber", quando o eurocentrismo se impõe como a única compreensão legítima do mundo, descartando a existência e a viabilidade de outros saberes e racionalidades epistêmicas, assim como outros conhecimentos que não sejam da mesma matriz androcêntrica, branca e setentrional.

\footnotetext{
${ }^{1}$ Ao lado do pensamento crítico renovado na América Latina e da valorização de suas fontes inspiradoras, somam-se, na crítica à história linear da modernidade, os Estudos Subalternos do Sul da Ásia, os Estudos Culturais na linhagem de Stuart Hall, as teorias do sistema-mundo que contestam as explicações dadas pela globalização hegemônica, e, ainda, as abordagens dos feminismos periféricos.
} 
Elegemos, no círculo da "modernidade-colonialidade-decolonialidade", o filósofo contemporâneo Enrique Dussel e o fazemos dialogar com o antropólogo brasileiro Darcy Ribeiro (1922-1997) a fim de observar o vigor de uma linhagem que possibilita hoje o "giro decolonial", fruto de um passado de acúmulo de pensamento crítico no continente sob novas injunções ${ }^{2}$. A partir de horizontes teóricos próprios, um após o outro retoma a utopia e propõe uma via alternativa à construção epistêmica eurosetentrional, formulando um conhecimento autóctone inovador que instiga a dúvida, a polêmica, tendo que, primeiro, destruir para abrir espaço para suas próprias construções; enfim, faz-nos pensar (Lecourt, 1978).

Darcy Ribeiro e Enrique Dussel atestam, ambos, que todo conhecimento é, de fato, sempre parcial, logo, não estaria povo algum "condenado" a uma interpretação exógena, mas lhe seria facultado pensar a si mesmo. A questão central, como chama atenção Ramón Grosfoguel (2010), é que a mudança do sujeito da fala desafiava o locus da enunciação consagrado para a produção de conhecimento, ou, como denomina o próprio Enrique Dussel, tendia a desestabilizar a geopolítica do conhecimento (apud Grosfoguel, 2010, p. 459). Em outras palavras:

$\mathrm{Na}$ filosofia e nas ciências sociais ocidentais, aquele que fala está sempre escondido, oculto, apagado da análise. A 'ego-política do conhecimento' da filosofia ocidental sempre privilegiou o mito de um 'Ego' não situado. O lugar epistêmico étnico-racial/sexual/de gênero e o sujeito enunciador encontram-se, sempre, desvinculados. Ao quebrar a ligação entre o sujeito da enunciação e o lugar epistêmico étnico-racial/sexual/de gênero, a filosofia e as ciências ocidentais conseguem gerar um mito sobre um conhecimento

\footnotetext{
${ }^{2}$ Não foi possível encontrar qualquer registro de que Ribeiro e Dussel tenham se conhecido pessoalmente ou, ao menos, trocado correspondências. O que de fato se sabe é que ambos os autores se leram, conheciam as ideias um do outro, e chegaram a se citar. Contudo, o que interessa aqui é articular este diálogo, ou seja, manifestar a compatibilidade entre os dois pensamentos reunidos aqui - cada qual de seu próprio modo - em torno de um fim epistêmico e utópico excepcionalmente bem orquestrado.
} 
universal verdadeiro que encobre, isto é, que oculta não só aquele que fala como também o lugar epistêmico geopolítico e corpo-político das estruturas de poder/conhecimento colonial, a partir do qual o sujeito se pronuncia. (Grosfoguel, 2010, p. 459)

Não é inocente, portanto, a inclinação, ainda presente e frequente no continente cultural latino-americano, como se fora 'natural', em não ler ou debater as correntes teóricas formuladas neste respectivo contexto, neste locus enunciador, submetendo-se, os centros de pesquisa e os cursos em níveis de graduação e de pós-graduação, a um certo colonialismo [que] faz com que leiamos com atenção os europeus ou norte-americanos, mas nunca os latino-americanos (Dussel, 1986a, p. 15). Em geral, copiamse as teorias e sistemas conceituais estrangeiros, que são utilizados e ensinados, com esmero, por nossos quadros universitários, mormente com uma ou mais etapa de formação no exterior, o que lhes propiciou o bom manejo da língua e a confiança de que trazem ao Brasil (ou à América Latina) as mais avançadas inovações em seu campo de saber. Podem estar certos, em parte. Dificilmente, porém, tal certeza advirá, se a produção intelectual latino-americana mais original não puder ser paritariamente conhecida e confrontada nos debates acadêmicos.

\section{Orientação para um diálogo a partir de Darcy Ribeiro}

Torna-se emblemático o relato de Darcy Ribeiro (1997), num prefácio redigido em 1978 à quarta edição venezuelana de seu livro O Processo Civilizatório, que confessava seu temor ao submeter pela primeira vez à publicação um trabalho de tal envergadura. Nesta apresentação, menciona que sua obra recebeu um parecer reprobatório de certo intelectual marxista - o qual Darcy toma a precaução de não nomear -, a partir do qual, entendeu a mensagem que, embora pudesse ser compe- 
tente, esquecera que intelectual do mundo subdesenvolvido tem de ser subdesenvolvido também (Ribeiro, 1997, p. 23). O parecer era arrasador, segundo Darcy, e indignado com o fato de que [...] o autor, etnólogo de índios, brasileiro, que não era nem sequer marxista, pretendia nada menos que reescrever a teoria da história, o que equivalia, [...] a inventar o moto-contínuo (Ribeiro, 1997, p. 23) ${ }^{3}$. Ora, este parecer explicitava uma colonialidade epistêmica ao determinar quem (não) poderia falar sobre o quê. Alegava ainda que estudos que traziam à cena os chamados povos pós-coloniais, de saberes divergentes dos europeus-setentrionais, eram insuficientes para uma reelaboração teórica da história mundial. E mais, o fato de a autoria não ser assinada por um francês, ou um britânico, um alemão, ou, um estadunidense, entre outros possíveis de se cogitar; mas de um estudioso "subdesenvolvido", um brasileiro, cujo lugar de enunciação é invisibilizado na história da ciência universal, não poderia garantir seriedade a seu empreendimento. Por fim, como última alegação de inviabilidade da obra darcyniana, está a questão mais significativa: é que seu autor não fez uso de um materialismo histórico-dialético rígido, ou seja, não se limitou a repetir de modo livresco as teses em voga, mas as reapropriou, ultrapassou.

Darcy Ribeiro foi um intelectual militante e pensador polímata. Exerceu funções e tarefas das mais diversas como antropólogo, educador, político, escritor, ensaísta e romancista, professor e "utopista", pois que se dedicou a estudar a América Latina e, de modo especial, o Brasil que acreditava poder e dever dar certo. Foi uma figura pública que alcançou

\footnotetext{
${ }^{3}$ Não foi possível confirmar com exatidão em qual editora foi primeiramente submetido seu texto. Mas cabe destacar que, após receber esta avaliação negativa, Darcy Ribeiro, contando com o apoio da arqueóloga norte-americana Betty Meggers, prosseguiu com o trabalho de edição e tradução do livro, e assim, conseguiu publicá-lo pela Smithsonian Institution, nos Estados Unidos, a mesma que havia também publicado as obras de Lewis Henry Morgan (18181881), o que veio a ser motivo de vaidade para o brasileiro (Ribeiro, 1997). No mesmo ano de 1968, Ribeiro também publicara sua primeira edição de O Processo Civilizatório no Brasil, pela Editora Civilização Brasileira, seguida de outras duas edições da obra até o ano de 1975.
} 
projeção e reconhecimento internacionais. Nascido em 26 de outubro de 1922, na cidade de Montes Claros, na região norte de Minas Gerais, Brasil, morreu em 1997, com 74 anos, respeitado como um brilhante intelectual por inúmeras vozes, jamais consensuais, em vista dos combates ideológicos que subjazem seus escritos. Assim como Enrique Dussel, Darcy sempre se definiu como "Homem de fé e de partido" (Ribeiro, 1997), seu pensamento e obra alinhavam-se aos ideais de uma sociedade solidária e emancipatória e, criativamente, retomava alguns clássicos para motivar desdobramentos mediante debates e reconstruções teóricas ${ }^{4}$. Jamais negou, pois, o cosmopolitismo do saber. Sua erudição era vasta. Ocorre que espanta alguns que não lhe atraía a reprodução, mas a "antropofagia" e suas fontes não eram se não material de trabalho para, no melhor sentido da dialética, promover inéditas sínteses. Também é de se notar que soube valorizar o pensamento quer dos cânones das ciências sociais quer de autores quase anônimos que, então, trazia à visibilidade.

Darcy Ribeiro, em seu intento de fazer notar a realidade latinoamericana, declara ser devedor de outros teóricos, como ele, "intelectuaismilitantes" que se propuseram, antes dele, a compreender a América Latina e fazer dela uma das expressões continentais mais progressivas, justa e próspera da terra (Ribeiro, 1995, p. 204). Entre numerosos nomes, é possível mencionar, no escopo deste artigo, o emblemático sergipano Manoel Bomfim, sobre o qual Darcy produziu um belo e elogiado ensaio atribuindo-lhe significativa influência na orientação de suas posturas e discussões.

O próprio Darcy relatou que, em seu primeiro exílio, em 1964, em Montevidéu, dedicou um longo tempo em pesquisas nas bibliotecas públicas uruguaias, lendo tudo o que conseguia do acervo acerca do assunto "América Latina", objetivando iniciar a escrita de seus Estudos de Antropo-

\footnotetext{
${ }^{4}$ Sobre tais apreensões da obra de Darcy Ribeiro, a título de exemplo, citamos trabalhos, entre outros, dos autores: Walter D. Mignolo (2003), Adelia Miglievich-Ribeiro (2011; 2013), Haydée Ribeiro Coelho (2012), Helena Bomeny (2001), Neusa Vaz e Silva (2009).
} 
logia da Civilização. Foi nesse período de intensas leituras e reflexões, que pôde romper com aquela que denominou uma perspectiva "simplista" e demasiadamente regionalista, visão que trazia consigo e ainda o impedia de perceber que a realidade brasileira fazia parte de um todo maior: a América Latina. É neste entremeio que lhe surge uma novidade:

No meio desse cipoal bibliográfico, às vezes surgia uma luz. Até sóis brilhavam ali, em cintilações fugazes de lucidez. Mas minha maior surpresa, meu encantamento, foi encontrar um dia, ao acaso, atraído pelo título, esse livro extraordinário que é A América Latina - Males de origem, de Manoel Bomfim. Lendo-o, me vi diante de todo um pensador original, o maior que geramos, nós, latino-americanos. Um pensador plenamente maduro em 1905, que foi quando publicou seu livro. (Ribeiro, 2005, p. 13).

É possível que Bomfim tenha acirrado em Darcy a atitude de confronto a uma "colonialidade do saber" que conseguiu, em tempo, perceber infrutífera e renovado nele a intrepidez em sua escrita e em seus sentimentos a levá-lo a novas formas de engajamento público. O que não deixa dúvida é que Darcy Ribeiro herdou de Bomfim seu pensamento social crítico (Miglievich-Ribeiro, 2013, p. 63). Darcy leu a obra de Bomfim como uma aventura em busca de uma utopia. Bomfim (2005) rejeitara, em América Latina: Males de Origem ([1905] 2005), aderir às ações e ideologias das elites que insistiam em explicar o "atraso" latino-americano por falsas suposições acerca da "raça" ou do "clima". Sua prioridade era revelar o sistema colonial como "parasitário", a extorquir as colônias e a fazer adoecer as metrópoles fadadas ao ócio. Contrariando todos que culpabilizavam os ex-cativos por um ethos supostamente antípoda ao trabalho, Bomfim construiu a tese de que, na colônia, haviam sido estes os únicos trabalhadores, ainda que o trabalho escravo lhes houvesse "roubado" a dignidade humana. Nesse sentido, a superação do "atraso" latino-americano passava pela aposta em seu povo realmente existente e 
na utopia de lhes devolver a plena humanidade, por meio de uma educação pública e de qualidade com a qual retomariam as rédeas de seu destino. Segundo Bomfim:

Utopia... Utopia... repetirá a sensatez rasteira, Utopia, sim; sejamos utopistas, bem utopistas; contanto que não esterilizemos o nosso ideal, esperando a sua realização de qualquer força imanente à própria utopia; sejamos utopistas, contanto que trabalhemos. Sem os utopistas de outrora, os homens viveriam, ainda hoje, nas cavernas, miseráveis e nus. São os utopistas que traçaram as linhas da primeira cidade. Dos sonhos generosos saem realidades benfazejas. A utopia é o princípio de todos os progressos e o esboço de um futuro melhor (2005, p. 382).

Cabe lembrar, porém, que, embora se reconheçam aproximações entre Bomfim e Darcy quanto ao que problematizavam e ao fato de que ambos defendiam posições progressistas, não menos no campo educacional, também havia certo distanciamento, de modo especial nas últimas obras de Bomfim ([1929] 1997) $)^{5}$. Não poderia ser de outro modo. Afinal, ambos os autores (e não só eles: todos) são indissociáveis do ambiente intelectual, histórico e político em que pensaram e escreveram a sua obra (Aguiar, 2000, p. 481). Enrique Dussel também defende perspectiva semelhante, ao pontuar que toda filosofia que não parte do real não é filosofia de verdade (Zimmermann, 1986, p. 43. cf.: Dussel, 1998): nossa realidade é a América Latina, um continente historicamente explorado

\footnotetext{
${ }^{5}$ Bomfim, diferentemente de Ribeiro, defendia que o termo "América Latina" não encontrava respaldo unificador na realidade, pelo contrário. Argumentava, como exemplo, que, nosotros - argentinos, peruanos, brasileiros, chilenos ... que somos os chamados latino-americanos, nunca pensamos em América Latina. Para os nossos conceitos de realidade ... nas relações comuns, ou como convergência de qualquer ação imediata, tal unidade não existe. (...) qualquer estrangeiro que aqui tenha feito vida conosco: falará de - Venezuela, Paraguai, México, Nicarágua ... mas nunca sentirá a necessidade de concentrar o espírito nesse conceito - América Latina. Em compensação, todos que não nos conhecem, se fazedores de teorias, com língua em coisas sociais, históricas, ou políticas, não falham no repetir de enfáticas e pueris preconceitos acerca da irreal unidade - América Latina (Bomfim, 1997, p. 31).
} 
e oprimido pelas potências ocidentais (e, é mister mencionar, "cristãs"). Com efeito, Manoel Bomfim viu a unidade latino-americana transfigurar-se num codinome reinventado pelos antigos e novos colonizadores para aviltar as "unidades nacionais soberanas" no continente. Viu-a transformar-se num "epíteto condenatório", ao invés de se constituir uma referência positiva acerca da unidade política e culturalmente constituída (Aguiar, 1996, p. 26). Darcy Ribeiro, nos anos 1960, retomou, entretanto, a expressão em sua força libertadora, buscando nela uma estratégia de autoafirmação dos povos do continente.

O primeiro esforço de Darcy Ribeiro visando a uma interpretação do Brasil, e que, posteriormente, se estenderia também para as Américas, começou na década de 1950, quando jamais cogitou não ser um dever pensar autonomamente sua própria sociedade. Foi no exílio que elaborou sua primeira tentativa interpretativa, contudo decidiu por não a publicar imediatamente retomando-a com este fim somente em 1969, compondo o quarto exemplar de sua série de estudos. O motivo é explicado por seu autor:

A primeira versão de OS BRASILEIROS foi redigida em Montevidéu, em 1965. Não publiquei então, porque sua própria elaboração demonstrou a carência de uma teoria interpretativa que me permitisse compreender efetivamente o processo de formação do povo brasileiro. Para isto seria necessário refazer previamente, a partir de uma perspectiva brasileira e latino-americana, uma série de esquemas teóricos. Primeiro, as teorias da história, particularmente o esquema marxista de sucessão das formações econômico-sociais, porque os disponíveis eram, evidentemente, inaplicáveis. Segundo, as classificações dos povos americanos e as análises comparativas das causas do seu desenvolvimento desigual, também inadequadas. Terceiro, as tipologias das classes sociais e das estruturas de poder que eram, por igual, insatisfatórias. Finalmente, os estudos críticos das culturas e das ideologias com vistas à avaliação das circunstâncias em que elas florescem ou fenecem e o seu papel no processo de dominação dos povos dependentes. (Ribeiro, 1985, p. 16) 
Confrontado com tais questões, Darcy elabora releituras e revisões que, paulatinamente, foram se avolumando e se tornando novos livros. Incomodava-o a ausência de uma teoria explicativa do Brasil, assim como da América Latina, situados numa ampla história humana, o que o impulsionava, portanto, a refletir sobre uma inovadora teoria da história. Darcy Ribeiro não encontrava possibilidades explicativas nas teorias conhecidas. Para ele, tais poderiam servir a uma versão teórica do desempenho europeu, mas não explicavam a história dos povos orientais, nem o mundo árabe e muito menos a nós, latino-americanos (Ribeiro, 1995, p. 14).

Assim, Darcy Ribeiro inicia uma revisão das teorias da evolução sociocultural, a fim de incluir devidamente as sociedades americanas - em especial latino-americanas - na história humana, em perspectiva autônoma e não restritamente vinculada à concepção e horizonte teóricos europeu. Darcy deixou claro que seu sentimento era o de que nos faltava uma teoria geral, cuja luz nos tornasse explicáveis em nossos próprios termos, alicerçada em nossas experiências na história, pois, teorizações oriundas de outros contextos eram todas elas eurocêntricas demais e, por isso mesmo, impotentes para nos fazer inteligíveis; constatando obviamente que, não possuindo o mesmo passado, nosso presente também não se coaduna com o deles, e assim, nem nosso futuro um futuro comum (Ribeiro, 1995, p. 13). Esta postura epistêmica cooperou para que se elaborasse uma crítica ao eurocentrismo dominante das teorias correntes sobre a evolução cultural. A revisão de tais teorias se daria com base em estudos críticos de nascente americana; não tendo como objetivo atribuir uma nova e inconsequente hegemonia, como aquela até então sustentada pela Europa, mas, pelo contrário, tinha o intuito de recolocar as sociedades humanas em sua totalidade, em uma linha comparativa de seus aspectos e processos de desenvolvimento (Ribeiro, 1978), o que já apresenta, nesta fase, um esforço em demonstrar uma perspectiva pluriversal na compreensão 
e produção do conhecimento. O livro O Processo Civilizatório: etapas da evolução sociocultural é a obra em que Darcy Ribeiro realiza tal revisão das teorias de evolução histórica.

Com o livro publicado em diversos idiomas, demonstrando seu pleno êxito apesar do primeiro parecer desabonador, Darcy Ribeiro criaria novas fontes de inquietação. O percurso interpretativo, em sua concepção, não estava de todo exaurido, sendo que as questões tratadas em $O$ Processo Civilizatório ainda não eram suficientes para tornar explicável sua "pátria continental". Com isso, propôs-se a uma nova abordagem e aproximação, de maior especificidade, com a América Latina. E assim, prosseguiu:

Saí, então, em busca de explicações mais terra-a-terra, em mais anos de trabalho. O tema que me propunha agora era reconstituir o processo de formação dos povos americanos, num esforço para explicar as causas do seu desenvolvimento desigual. Salto, assim, da escala de 10 mil anos de história geral para os quinhentos anos da história americana com um novo livro: As Américas e a Civilização, em que proponho uma tipologia dos povos americanos, na forma de uma ampla explanação explicativa. (Ribeiro, 1995, p. 15)

Desta feita, As Américas e a Civilização estabelece de modo consistente um empenho de interpretação antropológica de fatores complexos, de ordens sociais, culturais e econômicas na América, e que regeram a formação de suas etnias nacionais. Seu objetivo básico é proceder a uma análise das causas do desenvolvimento desigual das sociedades americanas (Ribeiro, 1983, p. 9).

A América Latina, segundo Darcy Ribeiro (1983), constitui-se como uma civilização antiga, assim como também são antigas as culturas ibéricas das quais os latino-americanos são herdeiros em plena simbiose com os africanos aqui chegados como mão de obra escrava. O "povo novo" nascido desta mistura ainda seria posto, pela fricção interétnica, em contato com as levas de imigrantes aportados no continente advindos de dis- 
tintas origens. No livro As Américas e a Civilização, esta concepção teórica constitui a gênese para a elaboração das tipologias étnico-nacionais de povos extraeuropeus, que serviu de fundamento a praticamente todos os textos escritos no período de exílio, objetivando o estudo e o conhecimento das diversas formações socioculturais na América Latina.

Tendo consciência da atuação e intervenção europeias reconfigurando a realidade histórica e cultural que virá a dominar nas Américas, Darcy propõe uma caracterização dos povos extraeuropeus para, então, delinear construtivamente uma perspectiva de desenvolvimento autônomo, em contraponto ao atraso histórico. Assim, Darcy Ribeiro explicitou uma classificação dos povos americanos do "mundo moderno", por meio de designações genéricas e aproximativas de diferentes povos por ele analisados. Cada uma delas engloba populações muito diferenciadas, mas também suficientemente homogêneas quanto às suas características básicas e quanto aos problemas de desenvolvimento (Ribeiro, 1983, p. 87) com que se confrontaram, legitimando-se, dessa forma, como categorias distintas. Esta classificação foi por ele denominada de "Configurações Histórico-Culturais". Tais tipologias étnico-nacionais são assim nomeadas: os Povos-Testemunhos, os PovosNovos, os Povos-Transplantados e os Povos-Emergentes.

Constatando Snão haver à disposição categorias teóricas para classificar, ou mesmo explicar, pelo seu grau de evolução, os povos latinoamericanos, uma vez que as tipologias usuais de então não conferiam condições suficientes para abarcar toda a gama de variações que se encontram na gênese do processo de formação da América Latina - pois nela se incluem desde tribos coletoras até altas e sofisticadas civilizações, sendo todas elas portadoras de culturas próprias, constituindo-se em expressões singulares - Darcy Ribeiro operou incomum esforço epistêmico. A questão diferenciadora que deste nasce é sua proposta de reformulação das concepções da evolução sociocultural, para servir de base aos estudos sobre o processo de formação étnica. 
Darcy Ribeiro realiza, em suma, uma revisão crítica da teoria evolucionista. Partindo de estudos reconhecidos como "clássicos" da evolução sociocultural, elabora um novo esquema do desenvolvimento humano, objetivando um estudo orientador da formação dos povos americanos, cuja principal inovação é a recepção crítica do conceito de "evolução multilinear", de Julien Steward, somada às contribuições de Leslie White, que Ihe permitiram demonstrar o caráter temporal e sincrônico das formações socioculturais concretas. Apresenta, assim, o que definiu como meta da investigação: as causas da desigualdade do desenvolvimento desses mesmos povos, que precisavam ser examinadas à luz do conceito de "aceleração evolutiva", formulado por ele em contraposição a outro, o de "modernização reflexa" ou "atualização histórica", que bem demonstra as variações nos processos de desenvolvimento de cada sociedade particular, levandose em conta o tipo de relação com as demais sociedades. Se os últimos expressam uma modernização conservadora e dependente, o primeiro liga-se à autodeterminação de um povo. Para Darcy, perguntar acerca de qual desenvolvimento a América Latina busca - ou que outros buscam para ela - é fundamental na compreensão de suas mazelas e de suas potencialidades.

Também Enrique Dussel mostra-se, ao lado de Darcy Ribeiro, um dos autores de maior significado e relevância para a interpretação sociocultural da América Latina. Similarmente, Dussel explicita a composição étnico-cultural dos povos americanos e coloca em pauta, consistentemente, um projeto epistêmico pluriversal, orientador e autônomo de unidade e composição de uma identidade latino-americana, que seja viável e realista a todos os cidadãos desta "Pátria Grande" (Ribeiro, 1986). 


\section{Orientação para um diálogo a partir de Enrique Dussel}

Enrique Dussel é um dos maiores expoentes da Filosofia da Libertação e importante referência do pensamento crítico latino-americano. Nasceu em La Paz, na cidade de Mendoza, Argentina, no dia 24 de dezembro de 1934. É exilado político desde 1975 no México, agora radicado neste mesmo país. Atualmente leciona no Departamento de Filosofia da Universidade Autônoma Metropolitana, em Iztapalapa, na Cidade do México, e também na Escola de Filosofia da Faculdade de Filosofia e Letras da Universidade Nacional Autônoma do México. Possui um doutorado em Filosofia pela Universidade Complutense de Madri, e um doutorado em História pela Sorbonne, em Paris, além de uma licenciatura em Teologia realizada em Paris e em Münster, na Alemanha. Sua rede de influências e interlocutores é vasta e proporcional a seu empenho crítico na busca de uma filosofia capaz de pensar a partir da América Latina, sem qualquer sentimento de inferioridade em face das maiores questões filosóficas postas pela história:

Desde 1952, na Universidade Nacional de Cuyo (Mendonza, Argentina), em sete ocasiões cursei o programa de ética (de inspiração aristotélica, tomista, fenomenológica, dentro da tradição de Max Scheler ou de D. von Hildebrand). Líamos Aristóteles em grego, Agostinho ou Tomás em latim. Descartes ou Leibnitz em francês, Scheler ou Heidegger em alemão. Seguidores democráticos que éramos de Jacques Maritain - contra o fascismo direitista de nossos professores - logo, ficamos conhecendo Emmanuel Mounier. Meu doutorado em Madri (1957-1959) sobre 'O bem comum' (desde os pré-socráticos até Kelsen, com Maritain e contra Charles de Konnick, despertou meu interesse pela filosofia política. A descoberta da miséria do meu povo, percebida desde a minha infância no campo quase desértico, levoume à Europa e à Israel. la, assim, descobrindo, como frisava o filósofo mexicano Leopoldo Zea, em sua obra 'América en la história" (1957) que a América Latina se encontra fora da História. Era preciso encontrar um lugar para ela na História 
Mundial, partindo da sua pobreza, e, assim, descobrir a sua realidade oculta. (Dussel, 2011, p. 13-4)

Ao longo de sua produção como teólogo, historiador e filósofo, dedicou-se com seriedade e sensibilidade a uma Ética da Libertação. Sobre Dussel, constata-se que, por onde passa, faz filosofia e, sobretudo, que o faz a partir de um horizonte latino-americano. Assim como Darcy, Dussel é um intelectual da práxis, dadas suas diversas atividades filosóficas e militantes na América Latina e no mundo. Ao que, trabalhando com categorias de pensamento específicas, identifica o caráter da dominação e avança no sentido da proposição de uma perspectiva de libertação (Hickert, 2005, p. 18).

As preocupações do filósofo argentino são colocadas a partir do paradigma prático de realidade ética do sujeito enquanto ser humano definido inicialmente pela sua corporalidade, em razão de suas necessidades físicas e sua autoconsciência. Desse modo, é capaz de conceder legitimidade às lutas de libertação de todos os povos oprimidos, especialmente, num processo excludente de globalização mundial (Dussel, 2000). A ética da libertação, segundo ele, é uma tentativa teórica que procura esclarecer uma práxis originada nas décadas de 1970-1980 diante do fracasso do "desenvolvimentismo" 6 . Pois, nos países periféricos e subdesenvolvidos, a produção de riqueza e sua distribuição para as imensas maiorias empobre-

\footnotetext{
${ }^{6}$ Dussel $(1987$, p. 258) entende que, o conceito negativo e pejorativo de 'desenvolvimentismo' (de 'desenvolvimento') quer indicar o caráter ideológico e falso da 'doutrina do desenvolvimento' (e das 'ajudas ao desenvolvimento') europeias e norte-americanas, predominantes nos meios cristãos (e na CEPAL). Contudo, podendo ter sido influenciado por Darcy Ribeiro, a compreensão deste conceito abarcará outras concepções, conforme Dussel esclarece: O critério e o principio ético de factibilidade [..] é constituído a partir de certas condições tecnológicas de possibilidade. O 'desenvolvimento civilizatório' - diria Darcy Ribeiro - torna possíveis hoje ações anteriormente impossíveis. Ampliou-se o horizonte de possibilidades. Da mesma maneira, ações possíveis no capitalismo tardio-central são ainda impossíveis no capitalismo periférico, não só pelo grau inferior de desenvolvimento tecnológico, mas também pelo grau de exploração (transferência estrutural de valor). [...] Ambos os condicionamentos (o tecnológico e o econômico) constituem condições de possibilidade da factibilidade de um objeto prático a realizar-se no futuro (Dussel, 2000, p. 265-6).
} 
cidas é impossível para o capitalismo e, portanto, Dussel assevera: a ética da libertação nasce como uma teoria antecedida e exigida por uma práxis que se opõe ao sistema como totalidade (Dussel, 1987, p. 259).

Aquele contexto, segundo o autor, evidenciava um problema que se tornou fundamental para sua construção filosófica e epistêmica, enunciado na questão: É possível uma filosofia latino-americana, africana, asiática, do mundo periférico? (Dussel, 1977, p. 176). A hipótese proposta por Dussel como resposta a esta questão, que encontra pleno paralelo em Darcy, é afirmativa e condicional. Em outras palavras, para o filósofo é possível filosofar a partir de qualquer contexto, contudo, assevera que: somente se não se imita o discurso da filosofia do centro, se se descobre outro discurso. Tal discurso, para ser outro radicalmente, deve ter outro ponto de partida, deve pensar outros temas, deve chegar a outras conclusões e com métodos diferentes (Dussel, 1977, p. 176).

Por meio de tal hipótese, Dussel pôde situar-se em uma história mundial, avançando de modo inovador quanto ao que se estava gestando na América Latina, reformulando o pensamento de forma original. Segundo ele, o que havia de novo neste contexto permanecia silenciado por uma filosofia eurocentrada. Portanto, além de esquadrinhar a construção ontológica do ser como absolutamente outro de cada sociedade, concomitantemente afirmou a exterioridade que subjaz em cada cultura, interpelando a totalidade e inaugurando uma nova etapa histórica.

Assim a América Latina é o Outro em relação ao centro (Europa - Estados Unidos - Rússia) assim como o é todo o Terceiro Mundo em relação ao Primeiro. A América Latina é tomada como um ser na sua globalidade, mas como um ser negado, historicamente negado; atualmente ainda negado. (Zimmermann, 1986, p. 44)

Discordando dos pós-modernos, Dussel não se preocupa em discutir "aquele outro, diferente da razão", mas, em 1976, quando nasceu a Fi- 
losofia da Libertação - antes, portanto, do dito movimento pós-moderno na Europa - expunha-se, sim, "a razão do Outro": do índio assassinado por genocídio, do escarvo africano reduzido a uma mercadoria, da mulher vilipendiada como objeto sexual, da criança subjugada pedagogicamente (Dussel, 2011, p. 47) ${ }^{7}$. A defesa era de uma racionalidade legítima, embora contrária ao eurocentrismo. A América Latina não era uma prémodernidade nem uma antimodernidade, sequer uma modernidade passível de se realizar como fazia crer Habermas.

\footnotetext{
${ }^{7}$ É oportuno comentar que, nas colônias ibéricas, de acordo com Darcy Ribeiro (1978; 1983), além de dizimada numericamente - flagelada pelas pestes com que o europeu a contaminou e desgastada sob o peso do trabalho, a população indígena minguava em proporções tão alarmantes que ameaçava desaparecer (Ribeiro, 1978, p. 172) -, aquela população se percebia degradada pela vicissitude de servir exclusivamente como mera mão-de-obra que, em si e para si, não encontrava qualquer possibilidade de existência própria, mas estava condicionada como produtora de determinados bens de proveito somente à economia do colonizador, sobretudo, metais preciosos. Enrique Dussel (1986b; 1993; 2010) atestou este argumento; contemporâneo e leitor de Darcy Ribeiro - como exemplo, em sua obra Método para uma filosofia da libertação, publicada originalmente em 1974, comenta e cita diretamente a obra darcyniana e, mais especificamente, o livro O processo civilizatório -, Dussel desenvolveu, durante toda sua carreira acadêmica, uma perspectiva de rompimento com essa referida postura econômica, política e ideológica levada à "ontologização", ou seja, em sua concepção, quando uma ideologia legitimadora do status quo promove opressão e morte (como feito pelo europeu) - dado que se exemplifica pelo radical fechamento do ser - e é limitadora do pensar alheio, pensar este que se faz sobre e a partir de uma determinada realidade (uma realidade distinta da do europeu). Este agravamento de uma ontologia levada ao dogmatismo religioso, que é concebida para outras realidades e prescrita a tais como a única verdade, é gerador de um completo encobrimento do outro. Isso fica emblemático quando, referindo-se à moderna filosofia europeia, Dussel esclarece que mesmo antes do ego cogito, mas certamente a partir dele, [a ontologia] situa todos os homens, todas as culturas, e com isso suas mulheres e filhos, dentro de suas próprias fronteiras como úteis manipuláveis instrumentos. A ontologia os situa como entes interpretáveis, como ideias concebidas, como mediações ou possibilidades internas ao horizonte da compreensão do ser. Espacialmente centro, o ego cogito constitui a periferia e se pergunta com Fernández de Oviedo: 'Os índios são homens?', isto é, são europeus e por isso animais racionais? O menos importante foi a resposta teórica; quanto a resposta prática, que é a real, ainda continuamos a sofrer: são apenas a mão-de-obra, se não irracionais, ao menos 'bestiais', incultos - porque não tem a cultura do centro -, selvagens... subdesenvolvidos (Dussel, 1977, p. 9). Assim, a ideologização da ontologia não aparece do nada, mas reduz a nada uma multidão. Por conseguinte, antes de um ego cogito sobreveio o ego conquiro, pelo qual um "centro" se impôs ao que considerou a "periferia". Este "eu conquisto" é o momento e ação anterior e, de acordo com Dussel (1977; 1993), é uma práxis; mas essa práxis se traduz por meio da opressão, da espoliação, do genocídio, do saque, da destruição, da negação.
} 
O debate entre Dussel e Karl-Otto Apel, bem como com Habermas, é de uma riqueza ímpar. Inspirado em Emmanuel Levinas e indo além, Dussel considera de modo privilegiado, na ação comunicativa, o ato de fala que recebe o nome de "interpelação", a qual buscaria na comunidade de comunicação as pretensões de validade (inteligibilidade, verdade, veracidade, retidão). Traz à luz, então, a interpelação por justiça do pobre excluído e evidencia como isso não é decodificado pelo outrocolonizador, algo como, diria Marx, fantasmas que ficam fora do seu reino (Marx apud Dussel, 2011, p. 54). Por exemplo, a assertiva: Aquele que luta pela libertação de seu povo é considerado criminoso sem que o seja, do mesmo modo, o tirano que subjuga uma nação. Evidencia-se aqui uma ausência de lógica. A interpelação não é ouvida, pois carece da inteligibilidade expressa num tipo específico de competência linguística que pessoas, culturas, comunidades periféricas não podem apresentar, já que pertencem a outro universo de sentidos. Por sua vez, a pretensão de verdade exigiria a aceitação do pressuposto de que o interpelante é "um de nós", algo que não se dá por princípio: ele é o bárbaro (e o excluído). Fica, também, débil a pretensão à veracidade da fala, que exige a crença na sinceridade do outro numa cena de comunicação assimétrica dada pela existência da colonização e da escravização. Eis que o que está sendo questionado pelo interpelante são as normas vigentes da institucionalidade hegemônica e a escuta desta fala exigiria, da parte da comunidade de comunicação, assumir a corresponsabilidade por ela. Por fim, a pretensão da retidão do interpelante está negada de início, pois tem sua dignidade de pessoa negada. A polêmica entre Dussel e Habermas se prolongará, ao ponto de aquele demonstrar que o decantado "mundo da vida" do segundo tem sobre a periferia o mesmo impacto que, em sua sociedade, a colonização sistêmica exerce. Na realidade, Dussel participa do debate filosófico europeu para esclarecer o quanto este é indiferente à outra face da modernidade: a colonialidade.

Da nossa parte, como latino-americanos, participantes de uma comunidade de comunicação periférica - dentro da 
qual a experiência da "exclusão" é um ponto de partida (e não de chegada) cotidiano, isto é, um 'a priori' e não um 'a posteriori' - nós precisamos obrigatoriamente encontrar o 'enquadramento' filosófico dessa nossa experiência de miséria, de pobreza, de dificuldade para argumentar (por falta de recursos), de ausência de comunicação ou, outra e simplesmente, de não-fazermos-parte dessa comunidade de comunicação hegemônica. (Dussel, 2011, p. 60)

Também no debate com Charles Taylor e com Richard Rorty ${ }^{8}$, Enrique Dussel quer contrapor um projeto filosófico latino-americano, uma filosofia hermenêutica da "cultura" latino-americana, que lhe sirva como perspectiva para elucidar e resistir à justificação dos movimentos históricos de dominação pelas filosofias articuladas no "centro" exitosas na promoção do mito de que a modernidade se trata de um fenômeno exclusivamente europeu, o que equivale a um encobrimento do outro.

A premissa é de que a modernidade surge quando a Europa se autodesigna como "centro" de uma História Mundial, que é por ela inaugurada e somente nela possui sua plena realização; e, por conseguinte, a "periferia" é um elemento de sua própria definição. Para nosso filósofo, o esquecimento desta 'periferia' [...] leva [...] a cair na falácia eurocêntrica no tocante à compreensão da Modernidade (Dussel, 1993, p. 7). Esta problemática acompanhou Dussel em todo seu itinerário filosófico, desde seus primeiros trabalhos em Filosofia da Libertação ${ }^{9}$, até seus textos

\footnotetext{
${ }^{8}$ Em abril de 1993, Dussel realiza, no México, um debate com Charles Taylor, cuja inspiração original pode ser lida em Projeto ético-filosófico de Charles Taylor e a filosofia da libertação. Escreve, ainda, Uma conversa com Richard Rorty ... partindo dos sofrimentos do outro por ocasião do Congresso Filosófico bienal na UAM/I, no México, em 1991. Enrique Dussel mantém a tônica, em suas duas argumentações, do quão pouco aceita é a "palavra" do Outro, se enquadrado em uma situação de exclusão econômico-política. Cf. Dussel, 2011.

${ }^{9}$ Roque Zimmermann (1986) apresenta um processo de três estágios no pensamento dusseliano, tendo uma mesma linha condutora-problematizadora. A primeira é nomeada como a fase ontológica, com inicio em 1961 até 1969, em que Dussel procura de-struir criticamente todo pensamento ontológico da filosofia ocidental desde os gregos até Heidegger. A segunda fase, de 1968 a 1976, intitulada por metafísica, que, inspirado em Ricoeur e Lévinas, tenta superar a dialética da ontologia da Totalidade opressor-oprimido, propondo um novo tipo de relação, com justiça e fraternidade. A terceira, nomeada simplesmente de mais concreta, estende-se de 1976 até a fase mais contemporânea; sendo uma fase de reflexão em contexto mexicano e, aqui, ganham mais importância suas análises críticas da obra de Karl Marx.
} 
mais recentes, e que tem estimulado produções teóricas de importantes intelectuais engajados em debates pós-coloniais e decoloniais. Como é o caso de Walter Mignolo, um dos mais destacados representantes da vertente da modernidade-colonialidade que, [...] elegeu Darcy Ribeiro, ao lado de Enrique Dussel e Aníbal Quijano, como seu interlocutor privilegiado (Miglievich-Ribeiro, 2012, p. 282-3) ${ }^{10}$. Este semioticista afirma que:

As "Indias Ocidentales", depois América e finalmente América Latina, foram duplamente constitutivas da modernidade através de sua particular diferença colonial. Em primeiro lugar, no século 16, a "descoberta" da América contribuiu para a formação do mundo colonial/moderno. Em segundo lugar, no início do século 19, as Américas contribuíram para constituir o segundo estágio da modernidade/colonialidade. Embora a "história" tenha enfatizado a Revolução Francesa, o lluminismo e a formação dos modernos estados-nações, a descolonização nas Américas caminha de mãos dadas com a história mais curta da modernidade (do século 18 até hoje). (Mignolo, 2003, p. 181)

Mas é necessário mencionar que isto se deu [em] face ao juízo depreciativo da existência de um 'Sul da Europa' (e por isso, da América Latina) construído epistemicamente pelo Iluminismo do centro e do norte da Europa desde os meados do século XVIII (Dussel, 2010, p. 341). Este lluminismo de fato "construiu" cerca de três categorias que eclipsaram qualquer

\footnotetext{
${ }^{10}$ Cabe aqui destacar que: O pensamento anticolonial de Darcy [e se pode acrescentar de Dussel] "conversa com o pensamento pós-colonial, sem se confundirem, pela ampliação do universal. Ambos atentam para a violência da colonização e suas sequelas nas dimensões econômica e simbólica da vida social. As estratégias subordinação e desumanização que produziram o colonizado, tornado 'espectador sobrecarregado de inessencialidade', produziram também o colonizador. A cultura-como-luta-política de Fanon autoriza a reorganização dialética da herança colonial que contém o gérmen de um povo livre. O contradiscurso pós-colonial e a descolonização podem, enfim, reinventar o sujeito na sua verdadeira humanidade, homens novos, portanto. Darcy Ribeiro ressaltara que, sob massacres, espoliação e intenso sofrimento, nasceram, nas Américas, os povos novos, mesclados na fusão de etnias" (MiglievichRibeiro, 2012, p. 300).
} 
exterioridade ${ }^{11}$ europeia. Dussel descreve, como primeira, o orientalismo, conforme elaborado pelo crítico literário palestino Edward Said; uma segunda seria o ocidentalismo eurocêntrico, plasmado emblematicamente no filósofo Hegel, e entre outros, e mais recentemente, também observado a partir do filósofo e sociólogo Jürgen Habermas. E por fim, a afirmação de existir um 'Sul da Europa'. Sobre este respectivo Sul, pontuou:

[...] foi (no passado) centro da história em volta do Mediterrâneo (Grécia, Roma, os impérios de Espanha e de Portugal, isto sem fazer referência ao mundo árabe do Magrebe, já desacreditado dois séculos antes), mas nessa altura já era um resíduo cultural, uma periferia cultural, porque, para a Europa setecentista que fazia a revolução Industrial, todo mundo Mediterrâneo era um 'mundo antigo'. (...) "nos Pirinéus começa a África", e as Américas Ibéricas, como é evidente, colocava-se como colônias dos já semiperiféricos Espanha e Portugal. Com isso, a América Latina simplesmente "desapareceu do mapa e da história" até hoje, inícios do século XXI. (Dussel, 2010, p. 342)

Esta compreensão histórica não abre oportunidade ao diálogo epistemológico pluriversal. Pelo contrário, autodetermina-se universal. Como enfrentamento, Dussel propôs-se a reinstalar a América Latina na geopolítica mundial - ou no processo civilizatório, diria Darcy -, assim como, na história das elaborações filosófica, científica e epistêmica. Em síntese, afirmou: A Europa nunca foi o centro da história mundial até finais do século XVIII (digamos, até ao século XIX, apenas há dois séculos); ocupando apenas uma posição central em decorrência da revolução Industrial, todavia, graças a uma miragem [...], aos olhos obnubilados do eurocentrismo toda a história mundial anterior Ihe aparece como tendo

\footnotetext{
${ }^{11} \mathrm{O}$ termo "exterioridade" é compreendido como categoria fundamental na filosofia dusseliana. Não apenas como novidade conceitual, mas principalmente como conteúdo inaugural de um discurso na história da filosofia mundial, pois alicerça a possibilidade concreta do encontro com o outro, tendo em tal encontro um "face-a-face", ou seja, um encontro entre "liberdade-liberdade"; algo antagônico a "superior-inferior"; "colonizador-colonizado" (ou, "colonizador-pós-colonizado"), ou ainda, simplesmente "útil-à-mão" (Dussel, 1977; 1986b).
} 
a Europa como centro, sendo o que distorce o fenômeno da origem da modernidade (Dussel, 2010, p. 344). Por meio desta assertiva, Dussel (2010) refuta uma elaboração histórica "iluminada", promulgada como gênese da modernidade. Esta compreensão, falaciosa segundo o filósofo argentino, é composta por pelo menos quatro movimentos: o primeiro seria o Renascimento italiano do Quattrocento; outro se refere à Reforma luterana alemã; e, acompanhados pela Revolução científica do século XVII, culminam no quarto movimento: a Revolução política burguesa inglesa, norte-americana e francesa. É mister observar a curva do processo: de Itália para Alemanha, daqui para França e depois para a Inglaterra e os Estados Unidos (Dussel, 2010, p. 343). Dussel rejeita esta construção por ser demasiadamente intraeuropeia, assim como claramente eurocêntrica e autocentrada, além de notoriamente ideológica, pois configura uma centralidade ao Norte da Europa, desde o século XVIII, e que ainda permeia o pensamento e compreensão contemporâneos ${ }^{12}$.

\footnotetext{
$\overline{12}$ É salutar a menção de que esta postura permanece permeando o labor teórico de vários intelectuais, sejam ou não latino-americanos, até os dias de hoje. Como exemplo, é possível citar as palavras do filósofo brasileiro Danilo Marcondes, quando trata das origens do pensamento moderno e da ideia de modernidade: O pensamento moderno talvez seja mais fácil de ser compreendido por nós, pelo fato de estarmos mais próximos dele do que do antigo e do medieval, e por sermos ainda hoje, de certo modo, herdeiros dessa tradição. [...] O conceito de modernidade está sempre relacionado para nós ao 'novo', àquilo que rompe com a tradição. [...] Na verdade, os grandes pensadores do séc. XVII, que podemos considerar como revolucionários e inovadores, por exemplo Bacon e Decartes, jamais se autodenominaram 'modernos', embora adotassem e defendessem, em grande parte, ideais associados à modernidade. A periodização histórica a que nos referimos acima origina-se, na realidade, basicamente do grande filósofo alemão do início do séc. XIX, G. W. F. Hegel (1770-1831). Hegel, foi, com efeito, o primeiro filósofo a elaborar uma filosofia da história, isto é, a entender a história da filosofia como uma questão central para a própria filosofia (Marcondes, 1998, p. 139). Esta história da filosofia descarta qualquer exterioridade europeia, pois é exclusivamente nela centrada, e conseguiu irracionalmente impor-se como hegemônica. Assim: Encarar a origem da modernidade com 'novos olhos' exige colocar-se fora da Europa germano-latina e vê-la como um observador externo [...]. A chamada Europa medieval, feudal ou da idade das trevas não é senão a miragem eurocêntrica que não se autodescobre desde o século VII como uma civilização periférica, secundária, isolada, 'enclausurada', 'sitiada' pelo - e perante o - mundo muçulmano mais desenvolvido e ligado à história da Ásia e da Africa até 1492 (Dussel, 2010, p.343).
} 
Desta feita, caso o labor teórico e utópico que Enrique Dussel pretendeu - e ainda continua a - defender seja verdadeiro, e aqui se sugere que o seja, é possível, a partir deste, ampliar novas possibilidades de investigação e enriquecedoras contribuições epistêmicas sobre o sentido e significado da modernidade filosófica e o consecutivo respeito e atenção dedicados em diálogos com os mais variados loci de enunciações. Tendo por certo que a modernidade não encontra seu início filosófico em Descartes (Dussel, 1993) - e este deve ser situado como o grande pensador do segundo momento da modernidade inicial, quando já se tinha produzido irreversivelmente a ocultação [...] do 'ser colonial' (Dussel, 2010, p. 390) -, abre-se, portanto, de modo legitimo, e também "irreversivelmente", um processo necessário e estimulante de descolonização epistêmica e científica.

\section{Considerações finais}

Articular um diálogo entre pensamentos tão amplos e complexos não é tarefa fácil. $\mathrm{O}$ intento neste espaço limitado foi modesto, mas de significativa importância: o de demonstrar a compatibilidade, e mais, a complementaridade entre as perspectivas darcyniana e dusseliana. Mesmo que cada qual construa sua obra e abordagem teórica de modo singular e situado, interessa aqui apontar que o fazem a partir de uma perspectiva latino-americana, contemplando um mesmo objetivo epistêmico e utópico libertador e autônomo.

Tanto em Darcy Ribeiro como em Enrique Dussel encontra-se a plena simbiose entre o teórico arguto e o militante apaixonado. Sobre Dussel, percebe-se que possui a coragem de dialogar de igual para igual com os melhores pensadores, sejam europeus, norte-americanos ou quaisquer outros, mas o faz por meio de categorias hermenêuticas novas. Não repete a filosofia do centro, e é ainda mais incisivo, não mais aceita 
que a filosofia seja um saber pelo mero prazer de saber, pelo contrário: a filosofia é concebida como um saber que está a serviço de uma transformação social. É um saber para uma práxis ou então, uma práxis que exige uma reflexão mais profunda (Zimmermann, 1986, p. 195-6).

Quanto a Darcy, na mesma senda, como poucos, aliou trabalho intelectual e político no sentido estrito (Mattos, 2007, p. 3). Seu empenho e responsabilidade - que julgava, deveria ter todo intelectual -, na elaboração de suas obras, as quais se confundem com sua caminhada "militante", foram os de um observador comprometido, que compara e interpreta, com a perspectiva orientada para a conjuntura do que foi e do que pode ser. Em sua obra-vida plasmou suas intenções; em suas palavras: quer ser, um gesto meu na nova luta por um Brasil decente. [...] Faço política e faço ciência movido por razões éticas e por um fundo patriotismo (Ribeiro, 1995, p. 17). Dedicou-se a escrever com uma consciência aguda e incisiva, advertindo para o que imaginou ser uma ameaça sobre os países latino-americanos, sua permanência como povo explorado, uma vez que alertava ser essa a proposta das classes dominantes nacionais em conivência com os interesses do capital internacional (Vaz e Silva, 2009; Ribeiro, 2015).

Estes dois intelectuais colocaram-se, a si mesmos, cada qual de seu próprio modo, não apenas como aquele que investiga objetivando alcançar uma constatação científica ou filosófica da realidade - isto não bastaria -, mas intentaram, tanto por meio do rigor científico quanto da tarefa militante e utopista, cumprir a responsabilidade que acreditavam ter o intelectual com respeito ao contexto em que vive. A perspectiva científica e antropológica do brasileiro e a histórica e filosófica do argentino estão comprometidas com o humano e se colocam a serviço dos povos que focalizam; que, neste caso, se refere à América Latina.

Darcy Ribeiro e Enrique Dussel são intelectuais latino-americanos que construíram de forma original uma perspectiva epistêmica autônoma, 
inovadora e salutar, de interpretação do contexto e do povo de nuestra América, imbuídos de um forte apelo a que tal episteme seja "pluriversal" (Mignolo, 2003). Em outras palavras, um apelo a um universal antagônico ao modelo eurocentrado, que é, portanto, unilateral, o que de outro modo, resultaria repetir os erros dos velhos algozes. Mas, ao superá-los, puderam incluir outras especificidades epistêmicas, favorecendo uma relação "transmoderna" e descolonizada; um encontro cultural, econômico, político e cognoscível com o Outro, um encontro sempre de "liberdadeliberdade". Talvez caiba, hoje, retomar suas teses principais, criticá-las, por certo, redimensioná-las e relocalizá-las em face de desafios que se acumulam no horizonte científico, filosófico e ético de uma humanidade que ainda parece refém da lógica poderosa da acumulação e da exclusão, dos neocolonialismos, do emprego constante da violência e da agressão militar. É possível pensar que há uma contribuição original a partir da periferia, não paroquialista, a oxigenar o debate cosmopolita.

Adelia M. Miglievich-Ribeiro é Doutora em Sociologia e pós-Doutora em Educação (UERJ), professora do departamento de Ciências Sociais e dos Programas de Pós-Graduação em Ciências Sociais e Letras da Universidade Federal do Espírito Santo (UFES, Vitória, ES, Brasil). \Mmiglievich@gmail.com

Edison Romera é sociólogo e teólogo. Mestre em Ciência Sociais pela Universidade Federal do Espírito Santo (UFES, Vitória, ES, Brasil). Pesquisador do Núcleo de Estudos em Transculturação, Identidade e Reconhecimento (NETIR) \edisonrjr@gmail.com 


\section{Referências}

1. AGUIAR, Ronaldo C. O rebelde esquecido: tempo, vida e obra de Manoel Bomfim. Rio de Janeiro: Topbooks, 2000.

2. BOMENY, Helena. Darcy Ribeiro: sociologia de um indisciplinado. Belo Horizonte: UFMG, 2001.

3. BOMFIM, Manoel. O Brasil na América: caracterização da formação brasileira. Rio de Janeiro: Topbooks, 1997.

4. BOMFIM, Manoel. América Latina: males de origem. Rio de Janeiro: Topbooks, 2005.

5. CASTRO-GÓMEZ, Santiago. Ciências sociais, violência epistêmica e o problema da "invenção do outro". In: LANDER, E. (Org.). A colonialidade do saber: eurocentrismo e ciências sociais latino-americanas. Buenos Aires: CLACSO, pp. 80-7, 2005.

6. COELHO, Haydée R. Darcy Ribeiro: a questão indígena, representação literária e suas múltiplas interfaces. O Eixo e a Roda: Revista de Literatura Brasileira, Belo Horizonte, v. 21, n. 2, p. 161-77, 2012.

7. DUSSEL, Enrique. Filosofia da libertação na América Latina. São Paulo: Loyola, 1977.

8. DUSSEL, Enrique. Prefácio. In.: ZIMMERMANN, R. América Latina o não-ser. Petrópolis: Vozes, 1986a. pp. 13-5.

9. DUSSEL, Enrique. Método para uma filosofia da libertação. São Paulo: Loyola, 1986b.

10. DUSSEL, Enrique. Ética comunitária. Petrópolis: Vozes, 1987.

11. DUSSEL, Enrique. 1492 o encobrimento do outro: a origem do mito da modernidade. Petrópolis: Vozes, 1993.

12. DUSSEL, Enrique. Autopercepción intelectual de un proceso histórico. Barcelona: Revista Anthropos, n. 180, p.13-36, 1998.

13. DUSSEL, Enrique. Ética da Libertação na idade da globalização e da exclusão. Petrópolis: Vozes, 2000.

14. DUSSEL, Enrique. Meditações anticartesianas sobre a origem do antidiscurso filosófico da modernidade. In.: SANTOS, B. S.; MENESES, M. P. Epistemologias do Sul. São Paulo: Cortez, 2010. pp. 341-95.

15. DUSSEL, Enrique. Filosofia da libertação. Crítica à ideologia da exclusão. São Paulo: Paulus, 2011. 
16. GROSFOGUEL, Ramón. Para descolonizar os estudos de economia política e os estudos pós-coloniais: transmodernidade, pensamento de fronteira e colonialidade global. In.: SANTOS, B. S.; MENESES, M. P. (orgs). Epistemologias do Sul. São Paulo: Cortez, 2010. pp. 455-91.

17. HARAWAY, Donna. Saberes localizados: a questão da ciência para o feminismo e o privilégio da perspectiva parcial. Cadernos Pagu, Campinas, n. 5, 1995. pp. 7-41.

18. HICKERT, Carmen. Enrique Dussel: o professor à luz do conceito de mestre em uma práxis pedagógica libertadora. São Leopoldo: Dissertação de Mestrado em Teologia, EST, 2005.

19. LANDER, Edgardo (org.) A colonialidade do saber: eurocentrismo e ciências sociais. Perspectivas latino-americanas. Ciudad Autónoma de Buenos Aires: Clacso, 2005.

20. LECOURT, Dominique. Para una crítica de la epistemología. Ciudad de México: Siglo Veintiuno Editores, 1978.

21. MARCONDES, Danilo. Iniciação à história da filosofia: dos pré-socráticos a Wittgenstein. Rio de Janeiro: Jorge Zahar, 1998.

22. MIGLIEVICH-RIBEIRO, Adelia M. Darcy Ribeiro e o enigma Brasil: um exercício de descolonização epistemológica. Revista Sociedade e Estado, v. 26, n. 2, p. 23-49, mai.-ago. 2011.

23. MIGLIEVICH-RIBEIRO, Adelia M. Darcy Ribeiro e a crítica pós-ocidental de Walter Mignolo: notas sobre processos civilizatórios nas Américas. Dimensões, v. 29, p. 281-308, 2012.

24. MIGLIEVICH-RIBEIRO, Adelia M. Intelectuais e Autoconsciência Latino-Americana: por uma crítica à razão ocidental. Realis. Revista de Estudos AntiUtilitaristas e Pós-Coloniais, Recife, v. 3, n. 2, p. 55-73, 2013.

25. MIGNOLO, Walter D. Descolonización epistémica y ética: la contribución de Xavier Albó y Silvia Rivera Cusicanqui a la reestructuración de las ciencias sociales desde los Andes. Revista Venez. de Econ. y Ciencias Sociales, v. 7, n. 3, set.-dez., p. 175-95, 2001.

26. MIGNOLO, Walter D. Histórias locais/ projetos globais. Colonialidade, saberes subalternos e pensamento liminar. Belo Horizonte: Edt. UFMG, 2003.

27. MIGNOLO, Walter D. Os esplendores e misérias da "ciência": colonialidade, geopolítica do conhecimento e pluri-versalidade epistêmica. In: SANTOS, Boaventura de Sousa (Org.). Conhecimento prudente para uma vida decente. 'Um discurso sobre as ciências' revisitado. São Paulo: Cortez, 2004, p. 667-709. 
28. QUIJANO, Aníbal. A colonialidade de poder, eurocentrismo e América Latina. In: LANDER, E. (Org.). A colonialidade do saber: eurocentrismo e ciências sociais latino-americanas. Buenos Aires: Clacso, 2005, p. 107-30.

29. RIBEIRO, Darcy. O Processo Civilizatório: etapas da evolução sócio-cultural. Petrópolis: Vozes, 1978.

30. RIBEIRO, Darcy. As Américas e a Civilização: processo de formação e causas do desenvolvimento desigual dos povos americanos. Petrópolis: Vozes, 1983.

31. RIBEIRO, Darcy. Os Brasileiros. Livro I - Teoria do Brasil. Petrópolis: Vozes, 1985.

32. RIBEIRO, Darcy. América Latina: a Pátria Grande. Rio de Janeiro: Guanabara, 1986.

33. RIBEIRO, Darcy. O Povo Brasileiro: a formação e o sentido do Brasil. São Paulo: Companhia das Letras, 1995.

34. RIBEIRO, Darcy. Prefácio à quarta edição venezuelana. In.: RIBEIRO, Darcy. O processo civilizatório: etapas da evolução sociocultural. São Paulo: Companhia das Letras, 1997.

35. RIBEIRO, Darcy. Manoel Bomfim, antropólogo. In.: BOMFIM, Manoel. América Latina: males de origem. Rio de Janeiro: Topbooks, 2005. pp. 11-22.

36. RIBEIRO, Darcy. Sobre o óbvio. In.: RIBEIRO, Darcy. Ensaios insólitos. São Paulo: Global, 2015.

37. SANTOS, Boaventura de Sousa. A crítica da razão indolente: contra o desperdício da experiência. São Paulo: Cortez, 2002.

38. VAZ E SILVA, Neusa. Teoria da cultura de Darcy Ribeiro e a filosofia intercultural. São Leopoldo: Nova Harmonia, 2009.

39. WALSH, Catherine. Interculturalidad, plurinacionalidad y decolonialidad: las insurgencias político-epistémicas de refundar el Estado. Bogotá: Tabula Rasa, no 9, julho-dezembro, 2008. pp. 131-152.

40. ZIMMERMANN, Roque. América Latina o não-ser. Petrópolis: Vozes, 1986.

Recebido: 17.08.2016

Aceite final: 28.04 .2017

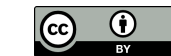

